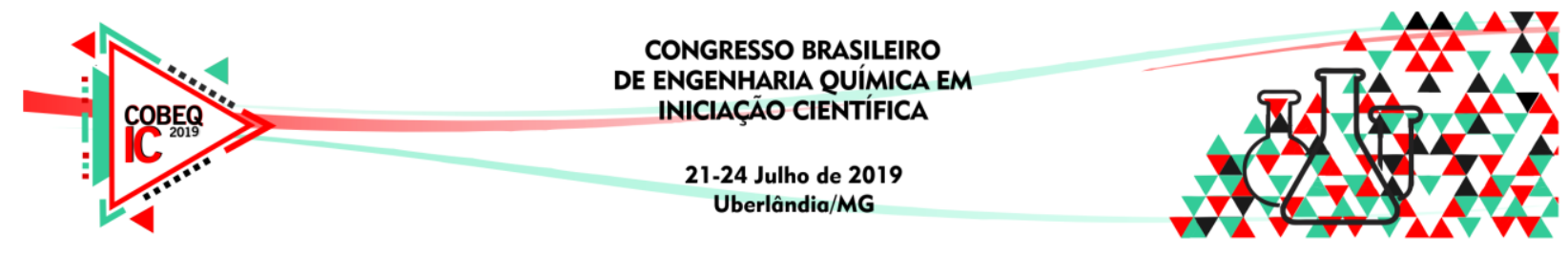

\title{
ESTUDO DE TRATAMENTO DE EFLUENTE TÊXTIL UTILIZANDO FLOCULAÇÃO COM POLÍMERO CATIÔNICO
}

\author{
A. G. PEREIRA ${ }^{1}$, J.V.W. DA SILVEIRA ${ }^{1}$ \\ ${ }^{1}$ Universidade Federal dos Vales do Jequitinhonha e Mucuri, Instituto de Ciência e \\ Tecnologia \\ E-mail para contato: arthurgomesp@hotmail.com
}

\begin{abstract}
RESUMO - As indústrias têxteis utilizam água em grande parte dos seus processos, gerando um efluente com grande carga poluidora; que pode ser tratado através da etapa de floculação seguida de sedimentação. Uma alternativa sustentável para este processo tem sido a utilização do polímero de tanino, material biodegradável, sintetizado a partir da acácia negra. Para este trabalho buscou-se avaliar dosagens e condições de operação do polímero catiônico de tanino em um efluente têxtil sintético. Variou-se a concentração de polímero entre 80 e $120 \mathrm{mgL}^{-1}$ e o pH de 8 a 9 para determinar a condição ótima de remoção de cor empregando um planejamento fatorial $2^{2}$, analisando-se turbidez, absorbância, velocidade de sedimentação e realizado um estudo estatístico desses resultados. Observou-se que o ensaio com concentração mínima utilizada $80 \mathrm{mgL}^{-1}$ e $\mathrm{pH} 8$ obteve melhor desempenho tanto de remoção de cor, quanto de velocidade de sedimentação, formando agregados visualmente maiores.
\end{abstract}

\section{INTRODUÇÃO}

Atualmente mais de um terço do planeta se encontra em situação de escassez de recursos hídricos; isso se deve a vários fatores. A necessidade de tratar e reciclar o efluente utilizado em diversos processos industriais, que devolveriam essas águas de forma a degradar o meio ambiente, fez com que se desenvolvessem formas de tratamento eficazes.

Para este estudo, consideramos um efluente sintético de indústria têxtil para ser tratado, de forma que este possa ser despejado em um corpo d'agua sem degradar o meio ambiente. A indústria têxtil caracteriza-se pela diversidade de processos envolvidos, além do alto volume de efluente de grande carga poluidora, sendo também ricos em produtos químicos incluindo corantes e pigmentos que contém metais pesados (CID et al., 1995).

Entre os métodos e tecnologias atualmente empregadas no tratamento do efluente têxtil estão os processos de adsorção em carvão ativado (CHUNG et al., 1992). Há também estudos relacionados ao ozônio, que é um gás incolor e ótimo agente oxidante. (BROWN et al., 1993). Em relação aos produtos e tecnologias usadas neste estudo, destacam-se os coagulantes químicos e os coagulantes catiônicos. 


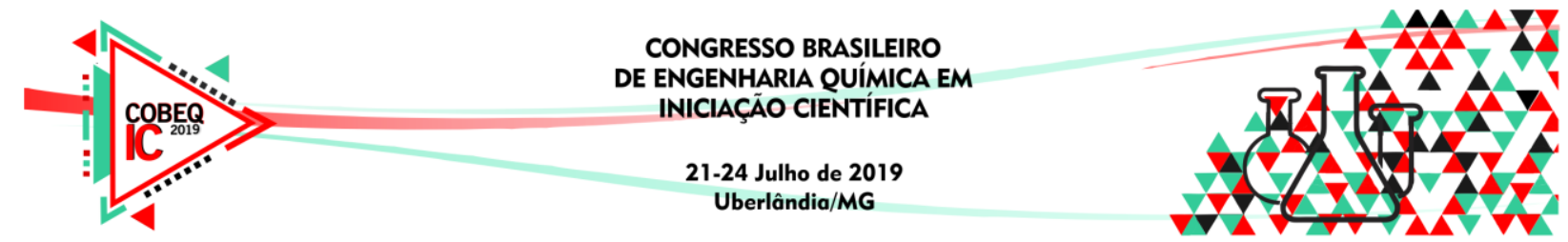

O coagulante catiônico Tanfloc SG, é um polímero orgânico-catiônico de baixo peso molecular, que atua em sistemas de partículas coloidais neutralizando suas cargas, desenvolvido e fabricado pela TANAC S.A. Neste contexto, foi avaliado o desempenho do polímero orgânico, tal como a otimização de operação, para que se obtenha a melhor eficiência no tratamento deste efluente, buscando diminuir a cor, turbidez e a toxidade originada dos produtos químicos utilizados.

\section{MATERIAIS E MÉTODOS}

Foram utilizados efluentes sintetizados em laboratório, em uma solução do corante TINGECOR GUARANY IND. E COM.LTDA de cor vermelha em $\mathrm{H}_{2} \mathrm{O}$ deionizada. Para coagulação foi utilizado o polímero catiônico de tanino Tanfloc SG, fornecido pela empresa TANAC S/A. Para a regulagem do $\mathrm{pH}$ ideal para realizar a sedimentação foi utilizado solução de $\mathrm{NaOH} 1 \mathrm{molL}^{-1}$.

\subsection{Métodos}

Foi usada a metodologia de Couto Júnior (2011), na qual se adiciona dosagens diferentes do coagulante em uma amostra de $1 \mathrm{~L}$, afim de encontrar a dosagem e o $\mathrm{pH}$ ótimo para o tratamento.

Foi preparada solução do efluente sintético a partir de $100 \mathrm{mgL}^{-1}$ de corante em $\mathrm{H}_{2} \mathrm{O}$ deionizada. As amostras de solução foram distribuídas em seis béqueres de 1L. O floculante Tanfloc SG foi empregado em concentrações entre 80 e $120 \mathrm{mgL}^{-1}$, e o pH foi controlado para uma faixa de 8 a 9 , sendo necessário utilizar solução de $\mathrm{NaOH} 1 \mathrm{molL}^{-1}$.

Em um equipamento Jar-Test - PoliControl foram adotados os tempos de 3 minutos para mistura rápida, e 10 minutos para mistura lenta, e posteriormente o período para análise da sedimentação foi de 12 horas. O clarificado foi retirado das amostras, e submetidos às análises de turbidez, a fim de avaliar a quantidade de sólidos particulados dispersos no clarificado. Também foi realizado também a análise da absorbância para obter a eficiência de remoção e consequentemente a ótima dosagem do coagulante e $\mathrm{pH}$ ideal para o tratamento. Para isto foi utilizado o espectrofotômetro Cirrus 80PE e uma cubeta de quartzo.

Para a análise e interpretação dos resultados foi utilizado um planejamento fatorial $2^{2}$ com repetição do ponto central, adotando-se o software Statistica versão 7.0, de modo a descobrir como o processo depende dos fatores concentração e $\mathrm{pH}$. A Tabela 1 representa $\mathrm{o}$ método de planejamento fatorial $2^{2}$, com os valores máximos $(+1)$, mínimos $(-1)$ e os dois últimos como repetição do ponto central (0). 


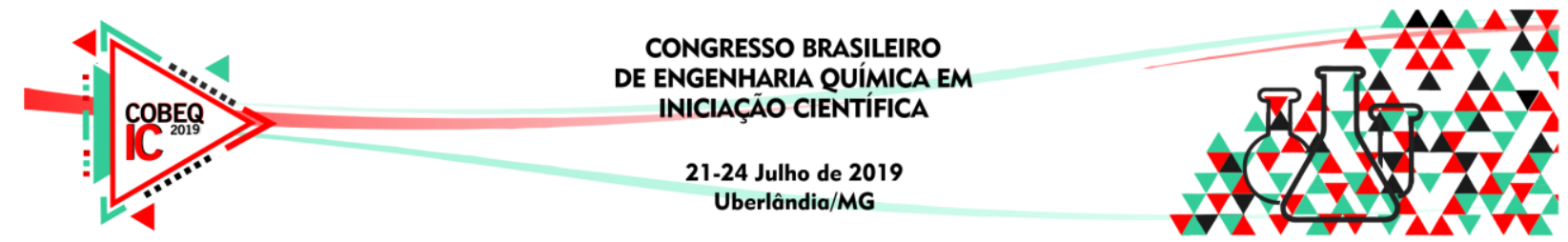

Tabela 1: Parâmetros de análise

\begin{tabular}{|c|rr|rr|}
\hline Ensaio & \multicolumn{2}{|c|}{ Polímero $\left(\mathbf{m g L}^{-1}\right)$} & \multicolumn{2}{|c|}{$\mathbf{p H}$} \\
\hline $\mathbf{1}$ & 120 & $(+1)$ & 9,0 & $(+1)$ \\
\hline $\mathbf{2}$ & 120 & $(+1)$ & 8,0 & $(-1)$ \\
\hline $\mathbf{3}$ & 80 & $(-1)$ & 9,0 & $(+1)$ \\
\hline $\mathbf{4}$ & 80 & $(-1)$ & 8,0 & $(-1)$ \\
\hline $\mathbf{5}$ & 100 & $(0)$ & 8,5 & $(0)$ \\
\hline $\mathbf{6}$ & 100 & $(0)$ & 8,5 & $(0)$ \\
\hline
\end{tabular}

\section{RESULTADOS E DISCUSSÕES}

O primeiro resultado a ser analisado foi do ensaio de sedimentação (Figura 1), em seis intervalos de duas horas, com exceção do primeiro intervalo de cinco minutos, que pareceu ter inicialmente um bom gradiente de sedimentação. As análises foram tomadas de acordo com a posição inicial $12 \mathrm{~cm}$ de altura equivalente à $400 \mathrm{~mL}$ de volume de amostra em uma proveta de 1 litro. Na medida em que a zona do clarificado aumentava, sua posição em relação ao ponto inicial diminuía

Figura 1 - Sedimentação nos intervalos de tempo

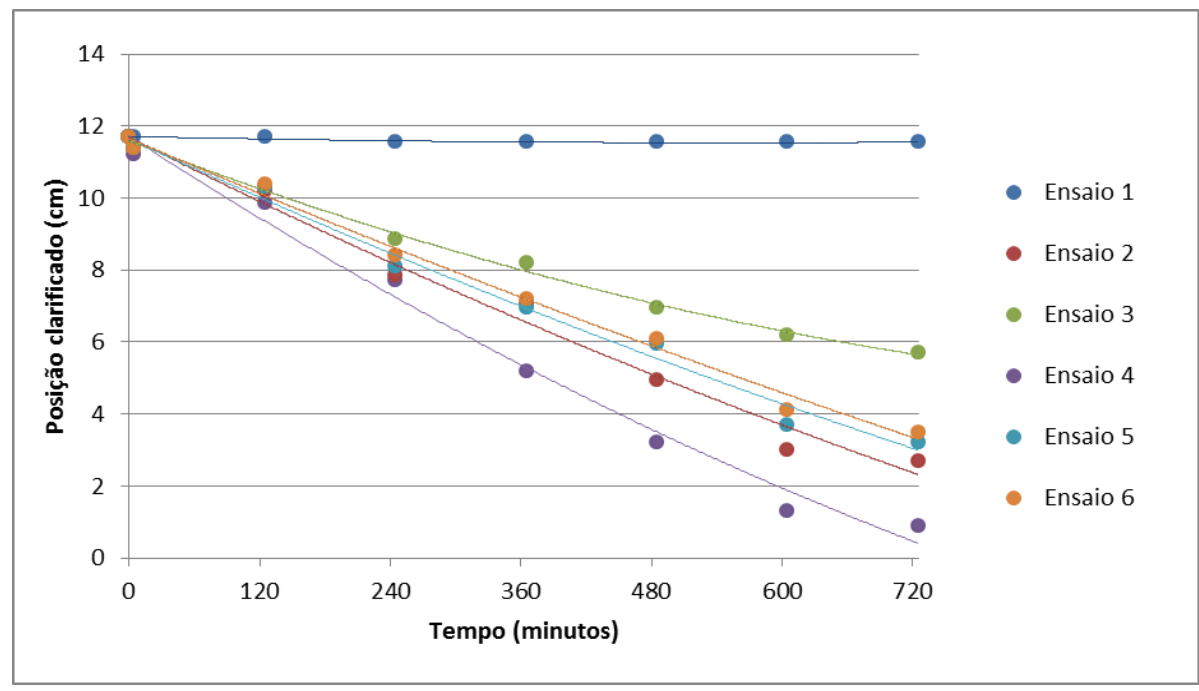

Apenas no ensaio 1 não houve sedimentação, apresentando uma única fase sólidos em suspensão no meio, em forma de pequenos flocos. $\mathrm{O}$ fato pode ser explicado devido à má formação dos flocos, com peso insuficiente para sedimentar, contendo uma única zona de partículas dispersas no meio.

O melhor resultado de sedimentação foi o ensaio 4, com concentração mínima de 80 $\mathrm{mgL}^{-1}$ e $\mathrm{pH} 8$, que apresentou um ótimo gradiente de velocidade em relação aos demais, com boa formação de flocos, formando zonas de sedimentação bem definidas. 


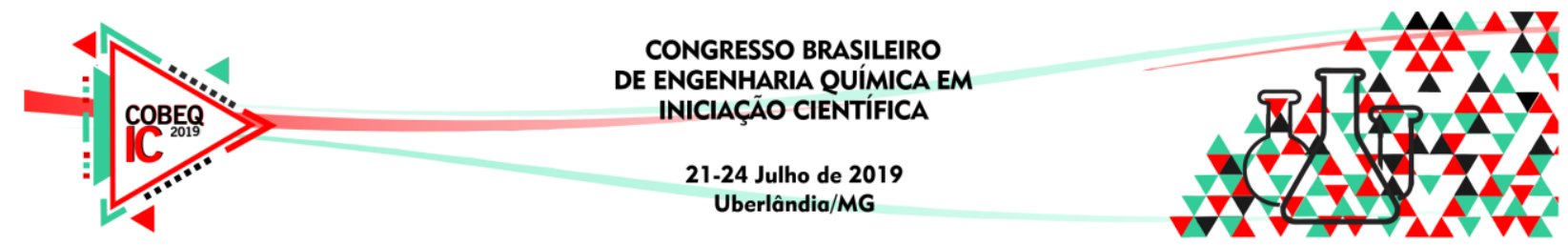

O resultado do ensaio de sedimentação, pode ser explicado devido ao fato do polímero em concentrações menores, ter a capacidade de agregar mais partículas em uma única unidade, desta forma vindo a formar flocos maiores que se aglutinam e sedimentam com maior velocidade. $\mathrm{O}$ pH teve grande importância na floculação. Como visto no ensaio 3, em que foi usada uma mesma concentração de polímero do ensaio 4, porém este apesar de formar flocos, o tamanho e peso foi inadequado para sedimentar. Isso pode ser explicado devido ao pH no meio estar mais elevado, ou seja, existe uma maior concentração de $\mathrm{NaOH}$, o que torna o meio menos adequado para que o corante interaja com o polímero.

Posteriormente, foram coletadas amostras do clarificado de cada ensaio, para realizar as análises de turbidez e absorbância. Foi analisado o parâmetro de turbidez dos clarificados, onde de acordo com a Tabela 1 pôde verificar que a amostra 1 resultou em alto valor de turbidez em relação aos demais; o fato pode ser explicado devido ao grande número de partículas sólidas e flocos que não sedimentaram e ficaram dispersos no líquido.

Utilizou-se o espectrofotômetro para obter a redução de concentração e cor do corante nas amostras dos efluentes tratados. Foi utilizada a leitura da absorbância $455 \mathrm{~nm}$, comprimento de onda do corante vermelho congo. Os valores das absorbâncias e turbidez coletados foram dispostos na Tabela 2 , em conjunto à concentração, $\mathrm{pH}$ e remoção de cor de cada amostra.

Tabela 2: Parâmetros de análise

\begin{tabular}{|c|c|c|c|c|c|}
\hline Amostra & $\begin{array}{c}\text { Concentração } \\
\text { Polímero (mgL }\end{array}$ & $\mathbf{p H}$ & $\begin{array}{c}\text { Turbidez } \\
\text { (NTU) }\end{array}$ & $\begin{array}{c}\text { Absorbância } \\
\text { (Abs) }\end{array}$ & $\begin{array}{c}\text { Remoção } \\
\text { de cor (\%) }\end{array}$ \\
\hline $\mathbf{1}$ & 120 & 9 & 5,8 & 0,059 & 0 \\
\hline $\mathbf{2}$ & 120 & 8 & 1,5 & 0,014 & 75 \\
\hline $\mathbf{3}$ & 80 & 9 & 1,89 & 0,030 & 48 \\
\hline $\mathbf{4}$ & 80 & 8 & 0,41 & 0,002 & 97 \\
\hline $\mathbf{5}$ & 100 & 8,5 & 1,66 & 0,010 & 82 \\
\hline $\mathbf{6}$ & 100 & 8,5 & 1,59 & 0,010 & 82 \\
\hline
\end{tabular}

Pode-se observar que houve uma variação na absorbância em diferentes amostras. A amostra 1 apresentou absorbância elevada em relação aos demais; isso pode ser explicado devido ao fato da amostra 1 ter utilizado uma concentração máxima, aumentando a cor e não realizando corretamente a coagulação/floculação. A amostra 4 obteve uma ótima redução de cor e absorbância, ou seja, a concentração de corante na amostra reduziu consideravelmente.

Pode se observar que o melhor resultado de remoção de cor foi o ponto mínimo (-1) dos parâmetros, ou seja, pH 8 e concentração $80 \mathrm{mgL}^{-1}$. Os intermediários, seguiram uma linha de tendência, assim como o ponto de repetição central. O pior resultado de remoção de cor foi o ponto máximo (+1), com pH 9 e concentração de polímero $120 \mathrm{mgL}^{-1}$, que pode ser explicado devido a má formação de flocos, que consequentemente veio a ter uma má sedimentação, permanecendo com partículas em suspensão. 


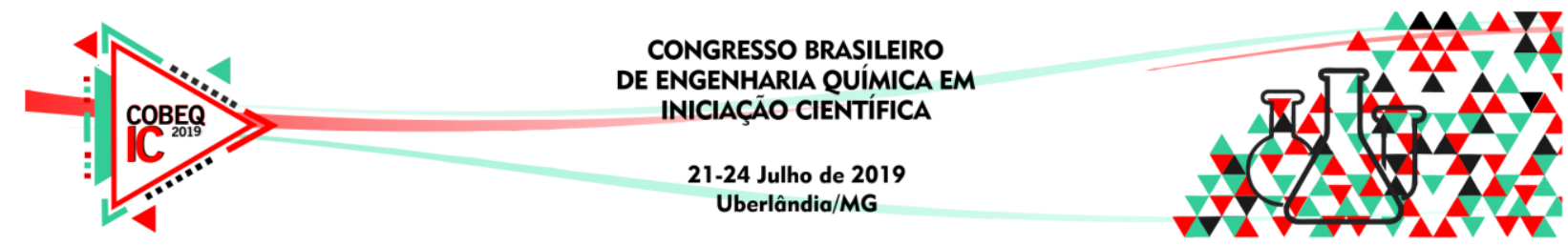

\section{CONCLUSÕES}

No presente trabalho, pode se através de diversos ensaios e análises determinar que o polímero a base de tanino é uma ótima alternativa sustentável para o tratamento de efluentes têxteis. A partir de um efluente têxtil sintético de $100 \mathrm{mgL}^{-1}$ de corante vermelho congo, foi determinado a melhor dosagem e condição para que o polímero Tanfloc SG tenha maior eficiência para o tratamento deste.

De acordo com todos os ensaios realizados, a amostra 4 obteve os melhores resultados, em uma concentração de $80 \mathrm{mgL}^{-1}$ e pH 8 . A velocidade de sedimentação dentro do período de doze horas foi superior aos demais. Além deste resultado, através da análise de turbidez e absorbância, foi confirmada uma melhor qualidade do clarificado nessas condições de operação.

$\mathrm{O}$ pH teve grande importância neste estudo, pois notou-se que em condições específicas haveria formação ou não de flocos neste tipo de efluente, e que por outro lado, a concentração máxima do agente floculante poderia vir a prejudicar a remoção de cor, acarretando também aumento da turbidez, devido ao excesso de material polimérico.

\section{REFERENCIAS}

CID, A.; HERRERO, C.; ENRIQUE, T.; ABALDE, J. ; Aquatic Toxicology. 1995, Volume 31, February 1995, p 31- 165.

CHUNG, K-T ; CERNIGLIA; C.E; Mut.Res. 1992, 277,201.

COUTO JUNIOR, O. M.. Tratamento de efluentes da indústria textil por coagulação e floculação utilizando polímeros naturais. 2011. 53f. Dissertação (Mestrado), Universidade do Estado de Maringá. Maringá-PR, 2011.

GUARATINI, C. C. I.; ZANONI, M. V. B. Corantes Têxteis. Quím. Nova, v. 23, p. 71-78, 2000. 